\title{
Veterinary
}

\section{Timing and presence of an attachment person affect sensitivity of aggression tests in shelter dogs}

\begin{tabular}{|r|l|}
\hline Journal: & Veterinary Record \\
\hline Manuscript ID: & vetrec-2013-101955 \\
\hline Article Type: & Paper \\
\hline Date Submitted by the Author: & $13-J u l-2013$ \\
\hline Complete List of Authors: & $\begin{array}{l}\text { Kis, Anna; Eötvös Loránd University, Department of Ethology; Hungarian } \\
\text { Academy of Sciences, Research Centre for Natural Sciences } \\
\text { Klausz, Barbara; Eötös Loránd University, Department of Ethology } \\
\text { Persa, Eszter; Eötvös Loránd University, Department of Ethology } \\
\text { Miklósi, Ádám; Eötvös Loránd University, Department of Ethology; MTA- } \\
\text { ELTE, Comparative Ethology Research Group } \\
\text { Gácsi, Márta; Eötvös Loránd University, Department of Ethology; MTA- } \\
\text { ELTE, Comparative Ethology Research Group }\end{array}$ \\
\hline \hline
\end{tabular}

SCHOLARONE

Manuscripts 
Timing and presence of an attachment person affect sensitivity of aggression tests in shelter dogs

Anna Kis ${ }^{1,2 *}$, Barbara Klausz ${ }^{1}$, Eszter Persa ${ }^{1}$, Ádám Miklósi ${ }^{1,3}$, Márta Gácsi $^{3}$

${ }^{1}$ Department of Ethology, Eötvös Loránd University, H-1117 Budapest, Pázmány P. 1/c.

${ }^{2}$ Research Centre for Natural Sciences, Hungarian Academy of Sciences, H-1132 Budapest, Victor Hugo 18-22.

${ }^{3}$ MTA-ELTE Comparative Ethology Research Group, H-1117 Budapest, Pázmány P. 1/c.

*kisanna12@gmail.com 


\begin{abstract}
Different test series have been developed and used to measure behaviour in shelter dogs in order to reveal individuals not suitable for re-homing due to their aggressive tendencies. However, behavioural tests previously validated on pet dogs seem to have relatively low predictability in the case of shelter dogs.

Here we investigate the potential effects of (1) timing of the behaviour testing, and (2) presence of a human companion on dogs $\square$ aggressive behaviour. In Study I, shelter dogs $(\mathrm{N}=25)$ showed more aggression when tested in a short test series two weeks after they had been placed in the shelter compared to their responses in the same test performed 1-2 days after arrival. In Study II, the occurrence of aggressive behaviour was more probable in pet dogs $(\mathrm{N}=50)$ in the presence than in the absence of their passive owner.

We conclude that the sensitivity of aggression tests for shelter dogs can be increased by running the test in the presence of a care taker and after some period of acclimatisation to the new environment. This methodology could also provide better chances for successful adoption.
\end{abstract}




\section{Introduction}

2 Millions of dogs are relinquished to animal shelters each year (e.g. Mondelli and others 2004;

3 Shore 2005; Tuber and others 1999). There is some evidence that physical characteristics such

4 as health, age, breed (e.g. New and others 2000) may play a role in relinquishment, but more

5 importantly, behavioural problems make it most likely that a dog ends up in a shelter (e.g.

6 Salman and others 2000; Mondelli and others 2004). Aggression is the most common

7 behavioural reason to surrender a dog to a shelter (van der Borg and others 1991; Salman and

8 others 2000; Stephen \& Ledger 2007; Diesel and others 2008), and also for the „euthanasia”

9 of healthy but not adoptable dogs in shelters (Marston and others 2004).

10 A large number of people are treated day by day in emergency rooms as a result of dog bites

11 (Newman and others 2010) carrying a pronounced financial impact (Overall \& Love 2001).

12 Shelter dogs with hidden aggressive tendencies can cause serious problems when re-

13 introduced to our society. This is probably the main motivation behind the development of

14 behavioural tests that could prevent the re-homing of aggressive dogs. Several complex

15 behavioural tests (e.g. Netto \& Planta 1997; Wilsson 1997; Plante \& De Meester 2007; van

16 der Borg and others 2010) and questionnaires (e.g. van den Berg and others 2010) developed

17 to measure aggression had already been validated on the pet dog population and some of them

18 were applied to shelter dogs as well (e.g. van der Borg and others 1991; De Palma and others

19 2005; Segurson and others 2005). However, these behaviour tests had a relatively low 20 predictive value in the case of shelter dogs, mainly due to the many false negative results 21 (Christensen and others 2007); a large proportion of dogs that had not showed aggression 22 during the test behaved aggressively after adoption.

23 The aim of the present study was to reveal some potential reasons for the low sensitivity of 24 aggression tests in the case of shelter dogs. In our first experiment we tested whether the 25 timing of the test (on the day of arrival or two weeks later) had an effect on shelter dogs' 
26 aggressive behaviour. In our second experiment we observed that in what extent and how the 27 absence or presence of the owners during the behavioural test altered pet dogs' aggressive 28 responses.

30 STUdY I

\section{Background}

32 According to our first hypothesis the inappropriate timing of the behavioural assessment 33 might contribute to the low sensitivity of aggression tests carried out in shelter dogs 34 (Christensen and others 2007). The cortisol level of shelter dogs is higher than that of pet 35 dogs at home environment, but it decreases with time spent in the shelter (Hennessy and 36 others 1997; Stephen \& Ledger 2006). Furthermore the cortisol level of shelter dogs is related 37 to timidity (Hennessy and others 2001) which could lead to suppressed behavioural 38 responsiveness, and parallel to this reacting with avoidance instead of confrontation to the 39 changes of environment. Based on these findings about shelter dogs' cortisol levels we 40 predicted shelter dogs to be more reactive, and therefore more motivated and showing more 41 aggression, in a behavioural test after spending some time in the shelter than right after 42 getting in.

\section{Method}

47 A total of 95 adult ( $>1$ year) shelter dogs participated in the test during a 5 months period in 48 the "Illatos út" Animal Health Institute, Budapest (Hungary). Twenty five dogs (17 male and 498 female, average age: $3.44 \pm 2.5$ years) could be retested two weeks after the first test and 50 were included in the detailed analysis (the others had been adopted, taken by breed-rescue 
51 associations, or claimed by the original owners before the second test). Due to the procedures

52

53

54

55

at the shelter we did not have any additional information about the subjects, for example the reason for surrender or about the owners that adopted them.

\section{Procedure}

Subjects were first tested one or two days after entering the shelter. We adopted a practical and short test procedure that proved to be effective in a recent study on a group of privately owned pet dogs (Klausz and others 2013). Our main consideration in choosing this test series was to cause the least stress possible to the dogs tested (the number of tests was reduced to a minimum thus testing was kept as short in duration as possible, while at the same time during all tests subjects had the possibility to choose between a fight or flight response as the experimenter never followed a dog that showed avoidance response). To guarantee the safety of the experimenter an artificial hand was used in tests with possible physical contact and the experimenter never entered the chain range of the dog.

All tests were carried out in a visually separated unfamiliar open-air area inside the shelter. Dogs were tethered to a tree and a spike (located about 3 meters from each other), with two 3 meter-long light chains in a V shape (Figure 1). This type of leashing prevents the dog from making semicircular movements, but allows it to move relatively long distances ahead and back.

The test series consisted of three tests with each test taking about 30-60 seconds. It was carried out with only a brief break (5-10 seconds) necessary to prepare the subsequent test, thus the whole test series took about 3 minutes per dog. Two female experimenters (E1: 29 years old and E2: 22 years old) participated in the test series with both of them being unfamiliar to the dogs. In Tests 1 and 2, E1 used an artificial hand. It was a very naturallooking model of a hand, made of plaster and covered with a glove. The artificial hand could 
76 be operated by a stick covered with a sleeve to hide the hand of the test-person. The behaviour

77 of the human participants was determined and standardized according to several 'If...then...'

78 rules.

79 Test 1 - Friendly greeting: E1 approaches the dog in normal walking speed while speaking in

80 a friendly manner to the dog and maintaining eye contact with it. She stops at $1 \mathrm{~m}$ from the

81 dog. Then, she calls the dog by its name, steps closer if the dog approaches her without

82 showing any sign of aggression, and strokes it gently on the head with the artificial hand. E1

83 continues calling the dog for $30 \mathrm{~s}$ even if it shows aggression or avoids her, but she never

84 goes closer than the chain range.

85 Test 2 - Take away bone: For this test we use a bone attached to a string. E1 gives the bone to 86 the dog to chew it while she holds the end of the string. The bone is always positioned a few 87 centimetres inside the chain range, so that the dog can choose either to approach the 88 experimenter and the bone or to avoid both of them. If the dog is motivated to chew the bone, 89 then after 5 seconds the experimenter strokes the dog's head with the artificial hand while 90 talking to it quietly ( $5 \mathrm{~s})$; then she reaches towards the bone, puts the hand on the bone and 91 says "Give it to me!"; then without saying anything holds her hand on the bone next to the 92 muzzle of the dog (5 s); finally, she takes away the bone from the dog by pulling the rope 93 with her other hand while the artificial hand remains on the bone pretending that she is pulling 94 the bone with it. The test is terminated if the dog a) tries to attack E1, b) allows her to take the 95 bone away, or c) is not motivated to chew the bone.

96 Test 3 - Threatening approach: E2 approaches the dog slowly, slightly leaning ahead and 97 staring into the dog's eyes (for detailed description see Vas and others, 2005). The test ends 98 when the experimenter reaches the chain range or when the dog reacts with aggression or 99 avoidance.

100 All tests were video recorded by the non-testing experimenter, and analyzed later. 
101 In order to assess possible behavioural changes two weeks after the first test dogs participated

102 in the same test series applying the same procedure, test place and experimenters.

103

104

\section{Data analysis}

105 We selected and defined the relevant variables (Table 1) based on the findings from an earlier 106 pilot study on 12 shelter dogs and on the results of our study on pet dogs (Klausz and others 107 2013). As Fear proved to be of crucial importance in the previous study by Klausz and others 108 we decided to thoroughly study related behaviours and coded Fear-submission and Anxiety109 discomfort using time $\%$ instead of $0 / 1$ score.

110 Inter-observer agreements between E1 and E2 for all variables were assessed by means of 111 parallel coding of 14 randomly chosen tests. High values were calculated in all cases (see 112 Cohen Kappa coefficients in Table 1).

113 We used paired t-test to compare the behaviour showed in the two tests in case of normally 114 distributed data (fear - submission and anxiety - discomfort) and nonparametric methods 115 (aggression: Wilcoxon signed-rank test; motivation: Chi-square test) when the data was not 116 normally distributed according to the Kolgomorov-Smirnov test.

\section{Result}

119 Generally the level of aggression was very low when dogs $(\mathrm{N}=95)$ were tested for the first 120 time, $1-2$ days after entering the shelter. In the friendly greeting test $1 \%$, in the take away 121 bone test $19 \%$ and in the threatening approach test $2 \%$ of the dogs showed some form of 122 aggression. Importantly, no difference was found in the responses of dogs that could not be 123 assessed in the second tests $(\mathrm{N}=70)$ and of those that were later retested $(\mathrm{N}=25)$ (for all tests $124 \mathrm{p}>0.05$, Mann-Whitney test). In order to resolve the unbalanced nature of the sample we took 125 a random sample of 25 subjects from the adopted population $(\mathrm{N}=70)$ and compared that to the 
126 re-tested sample $(\mathrm{N}=25)$. This comparison did not yield any significant results either (Friendly

127 greeting: $U=275.00, p=1.00$; Take away bone: $U=245.00, p=0.351$; Threatening approach:

$128 \mathrm{U}=264.00, \mathrm{p}=0.348)$.

129 Comparing the behaviour of dogs that participated in both test $(\mathrm{N}=25)$ we found that in the

130 friendly greeting test none of them showed any form of aggression on either occasion.

131 Furthermore we did not find any difference among the two occasions regarding fear -

132 submission $\left(\mathrm{t}_{(24)}=1.634 ; \mathrm{p}=0.115\right)$ and anxiety $-\operatorname{discomfort~}\left(\mathrm{t}_{(24)}=1.611 ; \mathrm{p}=0.120\right)$.

133 In the take away bone test, however, more dogs were motivated on the second occasion (3

134 dogs were not motivated in any of the two occasions, 7 dogs were only motivated on the 135 second occasion and 15 dogs were motivated on both occasions; $\left.\chi^{2}=5.114 ; p=0.024\right)$. Dogs

136 also showed more aggression towards the experimenter on the second occasion (15 dogs

137 showed no aggression in any of the two occasions, 5 dogs showed no aggression on the first

138 occasion, but growled on the second occasion, 3 dogs showed some aggression (1 growled, 2

139 snarled) on the first occasion and showed more severe forms of aggression (1 snarled, 2 bit

140 respectively) on the second occasion, while 2 dogs showed the same forms of aggression (1

141 snarled 1 bit) on both occasions; $\mathrm{Z}=2.640 ; \mathrm{p}=0.008$ ) (Figure 2).

142 In the threatening approach test only one dog was aggressive on both occasions. No

143 difference could be observed regarding fear - submission between the two test occasions

$144\left(\mathrm{t}_{(24)}=0.559 ; \mathrm{p}=0.581\right)$. However, for the second time dogs showed more anxiety - discomfort $145 \quad\left(\mathrm{t}_{(24)}=2.187 ; 0.039\right)$.

146 In sum, similarly to previous findings (Christensen and others 2007) we observed that in 147 general aggressive responses were rather rare in shelter dogs during the behaviour test (but 148 see van der Borg et al 1991). Nevertheless, the timing of the test (1-2 days after getting into 149 the shelter versus two weeks later) might have some influence in eliciting aggression from the 
150 dogs because our subjects showed more aggression in the take away bone test on the second

\section{1 occasion.}

152

\section{STUdy II}

\section{Background}

155 In Study I we found that testing dogs shortly after they had been placed in a shelter does not 156 sufficiently explain the low prevalence of aggression. Aggressive behaviours in our test were 157 also relatively rare even after our subjects had spent two weeks in the shelter. Comparing the 158 applied test procedure to that of conducted with owned pet dogs (Klausz et al 2013), one 159 important difference is that shelter dogs are tested in the absence of a human attachment 160 figure. Previous results suggest that this might be a notable difference because of dogs' 161 attachment towards their owners (Topál and others 1998; Prato-Previde and others 2003) 162 which implies that owners might serve as a secure base to dogs (Gácsi and others 2013).

163 Furthermore De Meester and others (2011) found some evidence that the presence and 164 absence of the owners explained most of the variance in a PCA study analysing postures and 165 behaviour strategies during the Socially Acceptable Behaviour Test.

166 Based on these previous findings, we assumed that dogs would show more aggression when 167 tested in the presence of a human partner, who can provide a secure base in conflict situations.

168 To test our hypothesis we observed and compared the behaviour of pet dogs in the same test 169 in the presence and in the absence of their owner.

\section{Method}

172 A total of 50 adult ( $>1$ year) pet dogs (from 24 different breeds and 15 mongrels, 22 males 173 and 28 females, mean age $3.72 \pm 2.32$ years) participated in the behaviour test described in

174 Study I. The subjects were randomly selected from a database containing approximately 900 
175 dog owners who had volunteered to participate in the behavioural tests of the Family Dog

176 Project of Eötvös University, Budapest. Subjects were tested individually in a visually

177 separated unfamiliar open-air area at the Top Mancs dog training school. All of them

178 participated twice in the same test series, once with the owner being present and once without

179 the owner. The two tests were performed in random order within a 1-3 weeks period. Both the

180 test procedure and the data analysis were executed in the same way as in the case of the

181 shelter dogs (for inter-observer agreement see Table 1).

182

\section{Result}

184 In the friendly greeting test two dogs showed aggression both with and without the owner,

185 while all other dogs showed no aggression on either of the two occasions. The presence of the

186 owner did not influence the fear - submission $\left(\mathrm{t}_{(49)}=0.379 ; \mathrm{p}=0.707\right)$, but we did observe a

187 higher level of anxiety-discomfort when dogs were tested without the owner $(Z=2.140$;

$188 \mathrm{p}=0.032)$.

189 No difference was found in the take away bone tests in the motivation of the subjects

$190\left(\chi^{2}=1.317 ; \mathrm{p}=0.251\right)$. Nevertheless dogs showed more aggression when tested with their

191 owners (40 dogs showed no aggression either with or without the owner, 8 dogs showed no

192 aggression without the owner, but growled (4), snarled (1) attacked (1) or bit (1) with the

193 owner, 1 dog showed some aggression (growled) without the owner but showed more severe

194 forms of aggression (bit) with the owner and 1 dog showed the same forms of aggression (bit)

195 both with and without the owner; $Z=2.354 ; \mathrm{p}=0.019$ ).

196 During the threatening approach dogs behaved more aggressively when tested with the owner

197 (32 dogs showed no aggression either with or without the owner, 12 dogs showed no

198 aggression without the owner but growled with the owner, 1 dog growled without the owner,

199 but snarled with the owner and 5 dogs growled both with and without the owner; $Z=2.673$; 
$200 \mathrm{p}=0.008$ ) (Figure 3) but we did not find any difference in fear-submission $\left(\mathrm{t}_{(49)}=0.110\right.$;

$201 \mathrm{p}=0.913)$ and anxiety-discomfort $(\mathrm{Z}=0.778 ; \mathrm{p}=0.437)$ related behaviours.

202 In sum, the results supported our hypothesis, that dogs show more aggression when tested 203 with their owners. This fact might explain the previously found low prevalence of aggression 204 in the case of shelter dogs that are always tested without a human partner.

\section{General discussion}

207 To our best knowledge in previous aggression tests timing has not been considered as an 208 important factor. Authors do not report the time dogs spent in the shelter prior to testing. One 209 exception is provided by Bollen \& Horowitz (2008) who claimed to test dogs only after 210 allowing them enough time to acclimatise to the shelter environment determined by the dog's 211 willingness to exit the kennel, run for walks and its willingness to eat and drink normally 212 while in confinement $($ minimum $=48 \mathrm{~h}$, maximum $=96 \mathrm{~h}$ ). However, the results by Stephen 213 \& Ledger (2006) suggest that in shelter dogs the level of cortisol does not return to baseline 214 levels until day 31, thus one can assume that dogs need to spend several weeks in the shelter 215 before their reactivity approaches appropriate levels. Our current findings suggest that dogs 216 show more aggression in a behavioural test after having spent two weeks in the shelter at least 217 in certain situations (take away bone). This observation seems to be in agreement with the 218 hormonal data (Hennessy and others 2001) because cortisol level returning to normal may 219 facilitate the emergence of aggressive behaviours thorough normalizing the responsiveness. 220 However, we cannot exclude the alternative hypothesis that the difference we found between 221 the first and the second test is due to an order effect (e.g. subjects being sensitized to 222 threatening stimuli), although in a previous study (Klausz and others 2013) we found that the 223 behaviour of pet dogs was consistent across time in the same test procedure. Moreover, other 224 authors (Svartberg and others 2005) have found that the intensity of aggression even 
225 decreased from test 1 to test 2 . In order to properly clarify this issue further studies are 226 needed.

227 Although our findings point out the importance of timing of the aggression test, based solely 228 on these results we cannot conclusively determine the time dogs need to spend in the shelter 229 before the aggression test so as to achieve maximum sensitivity. Therefore, further studies are 230 needed to examine aggression showed by shelter dogs after spending different amounts of 231 time in the shelter. Another important issue is that besides spending time passively in the 232 shelter and thus habituating to the new environment, human handling sessions can also reduce 233 cortisol levels in shelter dogs (Coppola and others 2006; Menor-Campos and others 2011). 234 These two factors might interact with each other and thus should be controlled carefully. A 235 further limitation from the applied perspective is that the tests we applied only measure 236 aggression directed towards strangers (Klausz and others 2013), whereas aggression towards 237 the owner and other family members is also a common complaint about dogs adopted from a 238 shelter (Christensen and others 2007).

239 We also revealed that the presence of the pet dogs' owners had a facilitating effect on dogs' 240 aggressive behaviour during the testing. This observation may help to explain the low levels 241 of aggression in shelter dogs in the present study and the low predictability of previous 242 aggression tests applied to shelter dogs (Christensen and others 2007). Gácsi and others 243 (2001) found that adult dogs in a shelter environment can form an attachment relationship 244 with an unfamiliar human only after a few handling sessions. Therefore such an attachment 245 person (e.g. the caretaker/handler of the dog) could play the role of the owner during the 246 aggression tests. The increased sensitivity of the test could be expected because the suggested 247 changes to the testing procedure mimic more closely the situation in real life. Furthermore 248 with the involvement of such a caretaker/handler additional test trying to assess (future249 )owner directed aggression might be carried out. 
1

2

3

4

5

6

7

8

9

10

11

12

13

14

15

16

17

18

19

20

21

22

23

24

25

26

27

28

29

30

31

32

33

34

35

36

37

38

39

40

41

42

43

44

45

46

47

48

49

50

51

52

53

54

55

56

57

58

59

60
250 In sum, we have provided evidence that time spent in the shelter and the presence of a human

251 companion affect the aggressive behaviour of dogs in test situations. Considering these

252 factors when evaluating shelter dogs could increase the predictability of adoption suitability. 253

254 Acknowledgement

255 We would like to thank the "Illatos út" Animal Health Institute and the Top Mancs dog school 256 for their help with recruiting subjects. The research was funded by the Hungarian Scientific 257 Research Fund (K 84036; K100695). 


\section{References}

BOLLEN, K., \& HOROWITZ, J. (2008) Behavioral evaluation and demographic information in the assessment of aggressiveness in shelter dogs. Applied Animal Behaviour Science 112, $120-135$

CHRISTENSEN, E., SCARLETT, J., CAMPAGNA, M., \& HOUPT, K. (2007) Aggressive behavior in adopted dogs that passed a temperament test. Applied Animal Behaviour Science 106, 85-95

COPPOLA, C.L., GRANDIN, T., \& ENNS, R.M. (2006) Human interaction and cortisol: can human contact reduce stress for shelter dogs? Physiology \& Behavior 87, 537-41

DE MEESTER, R.H., PLUIJMAKERS, J., VERMEIRE, S., \& LAEVENS, H. (2011). The use of the socially acceptable behavior test in the study of temperament of dogs. Journal of Veterinary Behavior: Clinical Applications and Research 6, 211-224

DE PALMA, C., VIGGIANO, E., BARILlARI, E., PALME, R., DUFOUR, A.B., FANTINI, C., \& NATOLI, E. (2005) Evaluating the temperament in shelter dogs. Behaviour 142, $1307-1328$

DIESEL, G., BRODBELT, D., \& PFEIFFER, D. (2008). Reliability of assessment of dogs' behavioural responses by staff working at a welfare charity in the UK. Applied Animal Behaviour Science 115, 171-181

GÁCSI, M., MAROS, K., SERNKVIST, S., FARAGÓ, T., \& MIKLÓSI, Á. (2013) Human analogue safe haven effect of the owner: behavioural and heart rate response to stressful social stimuli in dogs. PLoS ONE 8, e58475.

GÁCSI, M., TOPÁL, J., MIKLÓSI, Á., DÓKA, A., \& CSÁNYI, V. (2001) Attachment Behavior of Adult Dogs (Canis familiaris) Living at Rescue Centers: Forming New Bonds. Journal of Comparative Psychology 115, 423-431 
HENNESSY, M.B., DAVIS, H.N., WILLIAMS, M.T.., MELLOTT, C., \& DOUGLAS, C.W. (1997) Plasma cortisol levels of dogs at a county animal shelter. Physiology \& Behavior 62, $485-490$

HENNESSY, M.B., VOITH, V.L., MAZZEI, S.J., BUTTRAM, J., MILLER, D.D., \& LINDEN, F. (2001) Behavior and cortisol levels of dogs in a public animal shelter, and an exploration of the ability of these measures to predict problem behavior after adoption. Applied Animal Behaviour Science 73, 217-233.

KLAUSZ, B., KIS, A., PERSA, E., MIKLÓSI, Á., \& GÁCSI, M. (2013). A quick assessment tool for human-directed aggression in pet dogs. Aggressive Behavior accepted

MARSTON, L.C., BENNETT, P.C., \& COLEMAN, G.J. (2004) What happens to shelter dogs? An analysis of data for 1 year from three Australian shelters. Journal of Applied Animal Welfare Science 7, 27-47

MARSTON, L.C., BENNETT, P.C., \& COLEMAN, G.J. (2005) What happens to shelter dogs? Part 2. Comparing three melbourne welfare shelters for nonhuman animals. Journal of Applied Animal Welfare Science 8, 25-45

MENOR-CAMPOS, D.J., MOLLEDA-CARBONELL, J.M., \& LÓPEZ-RODRÍGUEZ, R. (2011) Effects of exercise and human contact on animal welfare in a dog shelter. Veterinary Record 169, 388.

MONDELli, F., PRATO-PREVIDE, E., VERGA, M., LEVI, D., MAGISTRELLI, S., \& VALSECCHI, P. (2004) The bond that never developed: adoption and relinquishment of dogs in a rescue shelter. Journal of Applied Animal Welfare Science 7, 253-266

NETTO, W.J., \& PLANTA, D.J.U. (1997) Behavioural testing for aggression in the domestic dog. Applied Animal Behaviour Science 52, 243-263

NEW, J., SALMAN, M.D., KING, M., SCARLETT, J.K.P., \& HUTCHISON, J. (2000) Characteristics of Shelter-Relinquished Animals and Their Owners Compared With 
Animals and Their Owners in U.S. Pet-Owning Households. Journal of Applied Animal Welfare Science 3, 179-201

NEWMAN, J., WESTGARTH, C., PINCHBECK, G., DAWSON, S., MORGAN, K., \& CHRISTLEY, R. (2010) Systematic review of human-directed dog aggression. Veterinary Record, 407.

OVERALL, K.L., \& LOVE, M. (2001). Dog bites to humans-demography, epidemiology, injury, and risk. Journal of the American Veterinary Medical Association 218, 1923

PLANTA, J., \& DE MEESTER, R.H. (2007). Validity of the Socially Acceptable Behavior (SAB) test as a measure of aggression in dogs towards non-familiar humans. Vlaams Diergeneeskundig Tijdschrift 76, 359-368

PRATO-PREVIDE, E., CUSTANCE, D.M., SPIEZIO, C., \& SABATINI, F. (2003) Is the dog-human relationship an attachment bond? An observational study using Ainsworth's strange situation. Behaviour 140, 225-254

SALMAN, M.D., HUTCHISON, J., RUCH-GALlIE, R., KOGAN, L., NEW, J., KASS, P., \& SCARLETT, J. (2000) Behavioral Reasons for Relinquishment of Dogs and Cats to 12 Shelters. Journal of Applied Animal Welfare Science 3, 93-106

SEGURSON, S., SERPELL, J., \& HART, B.L. (2005) Evaluation of a behavioral assessment questionnaire for use in the characterization of behavioral problems of dogs relinquished to animal shelters. Journal of the American Veterinary Medical Association 227, 1755-1761

SHORE, E.R. (2005) Returning a recently adopted companion animal: adopters' reasons for and reactions to the failed adoption experience. Journal of the American Veterinary Medical Association 8, 187-198

STEPHEN, J.M., \& LEDGER, R. (2007) Relinquishing dog owners' ability to predict behavioural problems in shelter dogs post adoption. Applied Animal Behaviour Science 107, 88-99 
STEPHEN, J.M., \& LEDGER, R. (2006) A longitudinal evaluation of urinary cortisol in kennelled dogs, Canis familiaris. Physiology \& Behavior 87, 911-916

SVARTBERG, K., TAPPER, I., TEMRIN, H., RADESATER, T., \& THORMAN, S. (2005) Consistency of personality traits in dogs. Animal Behaviour 69, 283-291

TOPÁL, J., MIKLÓSI, Á., CSÁNYI, V., \& DÓKA, A. (1998) Attachment behavior in dogs (Canis familiaris): A new application of Ainsworth's (1969) Strange Situation Test. Journal of Comparative Psychology 112, 219-229

TUBER, D.S., MILLER, D.D., CARIS, K.A., HALTER, R., LINDEN, F., \& HENNESSY, M.B. (1999) Dogs in Animal Shelters: Problems, Suggestions, and Needed Expertise. Psychological Science 10, 379-386

VAN DEN BERG, S.M., HEUVEN, H.C.M., VAN DEN BERG, L., DUFFY, D.L., \& SERPELL, J. (2010) Evaluation of the C-BARQ as a measure of stranger-directed aggression in three common dog breeds. Applied Animal Behaviour Science 124, 136-141

VAN DER BORG, J.A.M., BEERDA, B., OOMS, M., DE SOUZA, A.S., VAN HAGEN, M., \& KEMP, B. (2010) Evaluation of behaviour testing for human directed aggression in dogs. Applied Animal Behaviour Science 128, 78-90

VAN DER BORG, J.A.M., NETTO, W.J., \& PLANTA, D.J.U. (1991) Behavioural testing of dogs in animal shelters to predict problem behaviour. Applied Animal Behaviour Science 32, 237-251

WELLS, D., \& HEPPER, P. (2000). Prevalence of behaviour problems reported by owners of dogs purchased from an animal rescue shelter. Applied Animal Behaviour Science 69, 5565

WILSSON, E., \& SUNDGREN, P.E. (1997) The use of a behaviour test for the selection of dogs for service and breeding, I: Method of testing and evaluating test results in the adult 
dog, demands on different kinds of service dogs, sex and breed differences. Applied Animal Behaviour Science 53, 279-295 


\section{Table and figure captions}

Table 1 Names and definitions of the variables coded in the different tests

Figure 1 The schema of the test area

Figure 2 Aggression scores in the Take away bone test in Study I (median, quartiles, whiskers, outliers)

Figure 3 Aggression scores in the Threatening approach test in Study II (median, quartiles, whiskers, outliers) 


\section{Table 1}

\begin{tabular}{|c|c|c|c|c|}
\hline Test & Variable & $\begin{array}{l}\text { Type of } \\
\text { variable }\end{array}$ & Definition of the variable & $\begin{array}{l}\text { Cohen } \\
\text { Kappa }\end{array}$ \\
\hline \multirow{3}{*}{$\begin{array}{l}\text { Friendly } \\
\text { greeting }\end{array}$} & Fear - submission & $\begin{array}{c}\text { Time } \\
\text { percentage }\end{array}$ & $\begin{array}{l}\text { Tail wagging between the legs, dipped } \\
\text { head, tensed posture, lay on back }\end{array}$ & 1.0 \\
\hline & Anxiety - discomfort & Occurrence & Muzzle licking, scratching, yawning & 0.81 \\
\hline & Aggression* & Score & $\begin{array}{c}0 \text { - no aggression; } 1 \text { - growling, } 2 \text { - } \\
\text { snarling; } 3 \text { - snapping with/without } \\
\text { attack; } 4 \text { - biting }\end{array}$ & 1.0 \\
\hline \multirow{2}{*}{$\begin{array}{c}\text { Take away } \\
\text { bone }\end{array}$} & Motivation & $0 / 1$ & $\begin{array}{l}0 \text { - no motivation, } 1-\text { dog is in } \\
\text { physical contact with the bone: } \\
\text { holding, licking, chewing or laying on it }\end{array}$ & 1.0 \\
\hline & Aggression* & Score & $\begin{array}{c}0 \text { - no aggression; } 1 \text { - growling, } 2 \text { - } \\
\text { snarling; } 3 \text { - snapping with/without } \\
\text { attack; } 4 \text { - biting }\end{array}$ & 1.0 \\
\hline \multirow{3}{*}{$\begin{array}{l}\text { Threatening } \\
\text { approach }\end{array}$} & Fear - submission & $\begin{array}{c}\text { Time } \\
\text { percentage }\end{array}$ & $\begin{array}{l}\text { Tail wagging between the legs, dipped } \\
\text { head, tensed posture, lay on back }\end{array}$ & 1.0 \\
\hline & Anxiety - discomfort & Occurrence & Muzzle licking, scratching, yawning & 0.81 \\
\hline & Aggression* & Score & $\begin{array}{c}0 \text { - no aggression; } 1 \text { - growling, } 2 \text { - } \\
\text { snarling; } 3 \text { - snapping with/without } \\
\text { attack }\end{array}$ & 1.0 \\
\hline
\end{tabular}

* Score $0=$ no aggression (none of the following behaviours); Score 1 = growling (acoustic threats; low buzzing sound); Score 2 = snarling (the dog pulls up its upper lip, so that its teeth are visible); Score 3 = snapping with or without acoustic and visual threats with incomplete approach (the obvious aim of the biting, an open muzzled movement towards the artificial hand or arm, without the total contact with it); Score $4=$ biting with or without acoustic and visual threats (the artificial hand/arm totally gets into the jaws of the dog) - following Netto \& Planta (1997). Barking, staring, and the rigid posture without snarling or growling weren't noted as aggressive behaviour elements (following Christensen et al., 2007) 
Figure 1

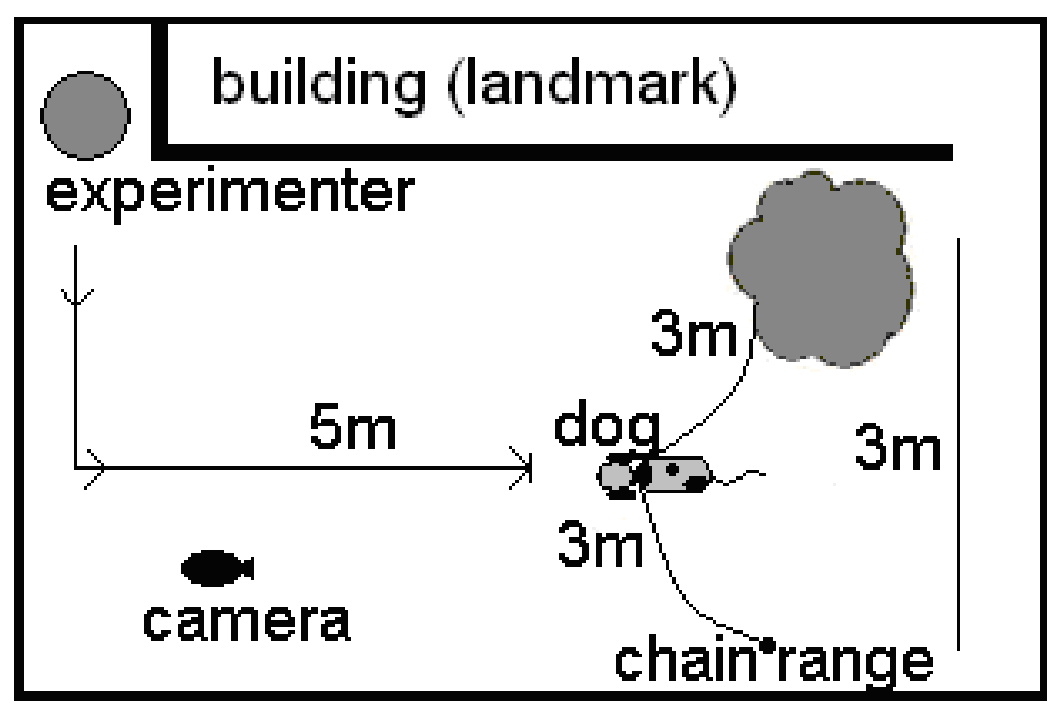

http://mc.manuscriptcentral.com/vetrec 
Figure 2

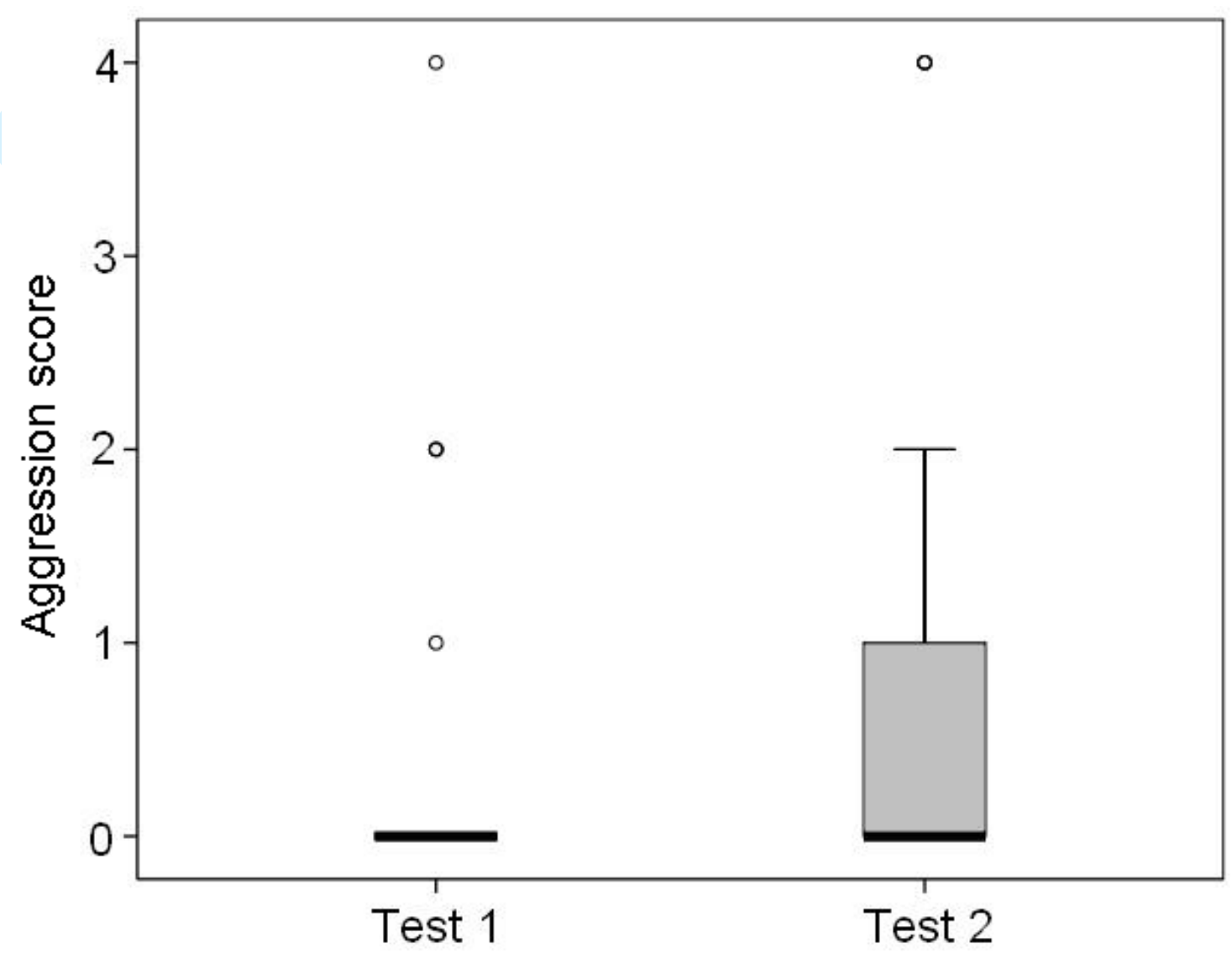

34

35

36

37

38

39

40

41

42

43

44

45

46

47

48

49

50

51

52

53

54

55

56

57

58

59

60

http://mc.manuscriptcentral.com/vetrec 
Figure 3



34

35

36

37

38

39

40

41

42

43

44

45

46

47

48

49

50

51

52

53

54

55

56

57

58

59

60

http://mc.manuscriptcentral.com/vetrec 